\title{
Lupus enteritis masquerading as Crohn's disease
}

\author{
Xiu-Li Zhu*', Xue-Mei Xu, Si Chen, Qiao-Min Wang and Kai-Guang Zhang
}

\begin{abstract}
Background: Systemic lupus erythematosus is an autoimmune disease which can affect multiple organs, resulting in significant mortality and morbidity. Lupus enteritis is one of the rare complications of SLE, defined as vasculitis of the intestinal tract, with supportive biopsy findings and/or image. However, lupus enteritis is seldom confirmed on histology or image and the changes of intestinal mucosa are nonspecific. Crohn's disease is a chronic inflammatory disorder of the gastrointestinal tract which affects any part of the gastrointestinal tract. The diagnosis of CD is confirmed by clinical evaluation and a combination of endoscopic, histology, radiology, and/or biochemical investigations.

Case presentation: Here we report a rare case of a 71-years-old Chinese male has been diagnosed with lupus enteritis which similar to CD in the aspects of endoscopic, histology, and radiology. So far, there are no relevant cases reported.

Conclusions: The endoscopic appearance of lupus enteritis is nonspecific, on the basis of our case, the features of lupus enteritis can be described as spacious, clean and no moss ulcers which discontinuous involved all gastrointestinal tract.
\end{abstract}

Keywords: Systemic lupus erythematosus, Crohn's disease, Lupus enteritis

\section{Background}

Systemic lupus erythematosus (SLE) is a multifactorial autoimmune disorder in which the body's immune system mistakenly attacks healthy tissue. The disease is gender-related occurring nine times more likely in women than men, especially in women of child-bearing years (15 to 35 years old) [1]. SLE usually damages the heart, joints, skin, lungs, blood vessels, kidneys, and nervous system. In recent years, some studies have reported that SLE also harms gastrointestinal tract and lupus enteritis as an initial manifestation of SLE. There is no standard definition of lupus enteritis, most scholars believe that lupus enteritis is vasculitis or intestinal inflammation with supportive images and/or biopsy results. But it is so difficult to diagnose lupus enteritis relying on histology and radiology in the clinic. Crohn's disease

\footnotetext{
* Correspondence: 1216243099@qq.com

Department of Gastroenterology, Anhui Provincial Hospital, Hefei, Anhui

230001, People's Republic of China
}

(CD) is a lifelong disease caused by the interaction between infectious, immune, genetic and environmental factors. A single gold standard for the diagnosis of $C D$ is not available. The current view is that diagnosis is based on a combination of clinical manifestations, endoscopic appearance, radiology, histology, and surgical outcomes, however, this still results in diagnostic obstacles [2]. The two diseases are rare and the diagnosis is difficult. The following case describe an old male presenting with lupus enteritis and diarrhea as the initial manifestation of SLE, but in terms of endoscopy, histology, and radiology, the case is similar to CD. To the best of our knowledge, there are no relevant cases reported in the English literature.

\section{Case presentation}

A 71-year-old Chinese male with no significant medical history was admitted to the department of gastroenterology in our hospital with three months of watery diarrhea and mild abdominal pain. The patient described the

(C) The Author(s). 2019 Open Access This article is distributed under the terms of the Creative Commons Attribution 4.0 International License (http://creativecommons.org/licenses/by/4.0/), which permits unrestricted use, distribution, and reproduction in any medium, provided you give appropriate credit to the original author(s) and the source, provide a link to the Creative Commons license, and indicate if changes were made. The Creative Commons Public Domain Dedication waiver (http://creativecommons.org/publicdomain/zero/1.0/) applies to the data made available in this article, unless otherwise stated. 

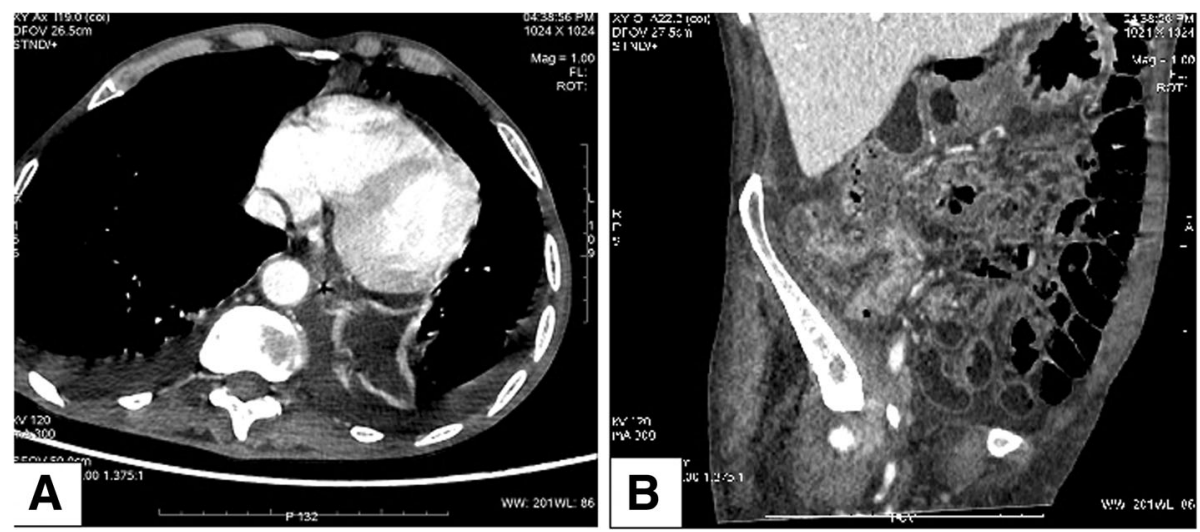

Fig. 1 Chest and abdominal enchaned CT revealed polyserositis (pleural effusion, ascites, pericardial effusion) (a) and marked thickening of the entire colonic mucosa (b)

diarrhea frequency was six to ten times per day without mucoid or blood. Physical examination revealed one oral ulcer, tenderness of the abdomen without rebound tenderness and shifting dullness. Laboratory tests revealed a leukocyte count of $12.5 * 10^{9} / \mathrm{L}$, anemia (hemoglobin of $67 \mathrm{~g} / \mathrm{L}$ ) and a positive antinuclear antibody titer of 1 : 3200, positive serology for the antiphospholipid antibody. Erythrocyte sedimentation rate (ESR) and Creactive protein (CRP) were $130 \mathrm{~mm} / \mathrm{h}$ and $117 \mathrm{mg} / \mathrm{L}$, respectively (normal: $0-15 \mathrm{~mm} / \mathrm{h}$ and $0-8 \mathrm{mg} / \mathrm{l}$, respectively). Complement components $\mathrm{C} 3$ and $\mathrm{C} 4$ were $50 \mathrm{mg} /$ $\mathrm{dL}$ and $12 \mathrm{mg} / \mathrm{dL}$, respectively (normal: $86-160 \mathrm{mg} / \mathrm{dL}$ and $17-45 \mathrm{mg} / \mathrm{dL}$, respectively). Syphilis serology and TPPA/TPHA, TRUST were positive. PPD experiment and $\mathrm{T}$-spot test were negative. Fecal routine, fecal bacteriological tests (C.difficile, Salmonella, Campylobacter, Yersinia and many more) and fecal virological tests were all normal. Contrast-enhanced computed tomography (CT) of the chest and abdomen revealed polyserositis (pleural effusion, ascites, pericardial effusion) and marked thickening of the entire colonic mucosa (Fig. 1).
Ascites routine revealed pale yellow and Rivalta test(+), quantitative counting of nucleated cells were $462^{*} 10^{6} / \mathrm{L}$ and monocytes (72\%), coenocyte (27.7\%). Electronic colonoscopy showed multiple ulcers in the terminal ileum and colon which were circular, wide, clean, without moss and hyperplastic lesions around the anus (Fig. 2). The pathology tended to $\mathrm{CD}$ because there were ganglion cell and crack shape ulcer (Fig. 3). Gastroscopy showed no obvious abnormalities in another hospital.

Through the case discussion in the multi-disciplinary team (MDT) including histology, radiology, rheumatology, and gastroenterology we diagnosed the patient with lupus enteritis prior to $\mathrm{CD}$. Then the patient was given systemic steroids (Solu-Medrol $80 \mathrm{mg}$ QD) and within a few days (7-10 days) the abdominal pain and diarrhea began to resolve. The patient was discharged on a tapering dose of steroids (Prednisone $50 \mathrm{mg}$ QD). The CRP, ESR, Complement components $\mathrm{C} 3$ and $\mathrm{C} 4$ were normal after two months.

However, the patient complained of bloating after a meal three months after discharge, gastroscopy combined

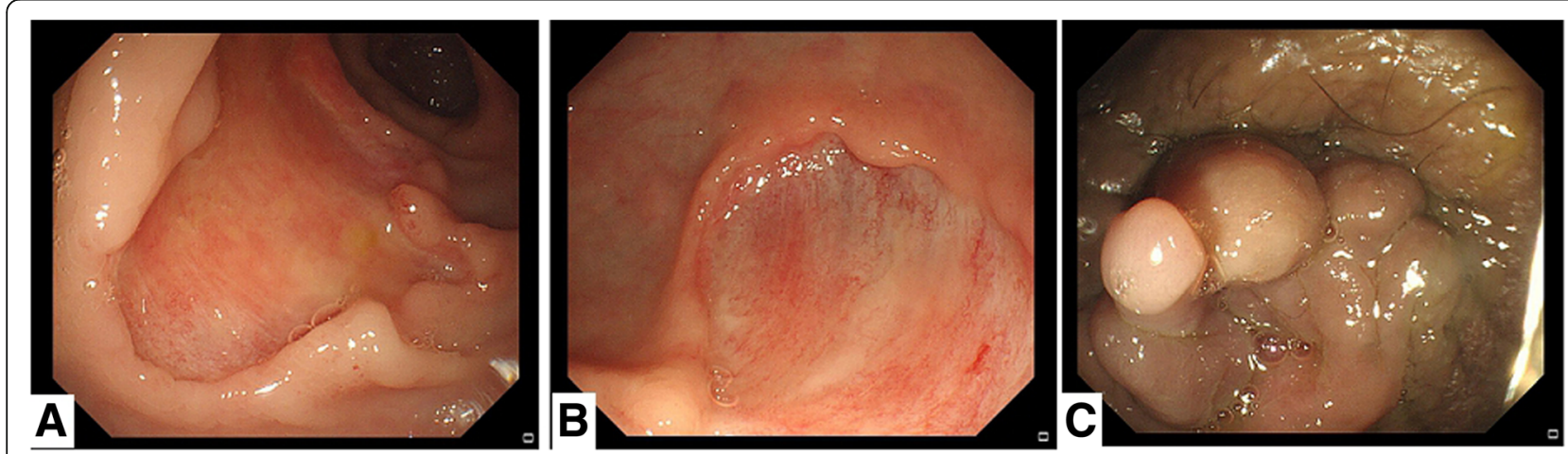

Fig. 2 Electronic colonoscopy showed multiple ulcers in the terminal ileum and colon which were circular, wide, clean, without moss (a, b) and hyperplastic lesions around anus (c) 

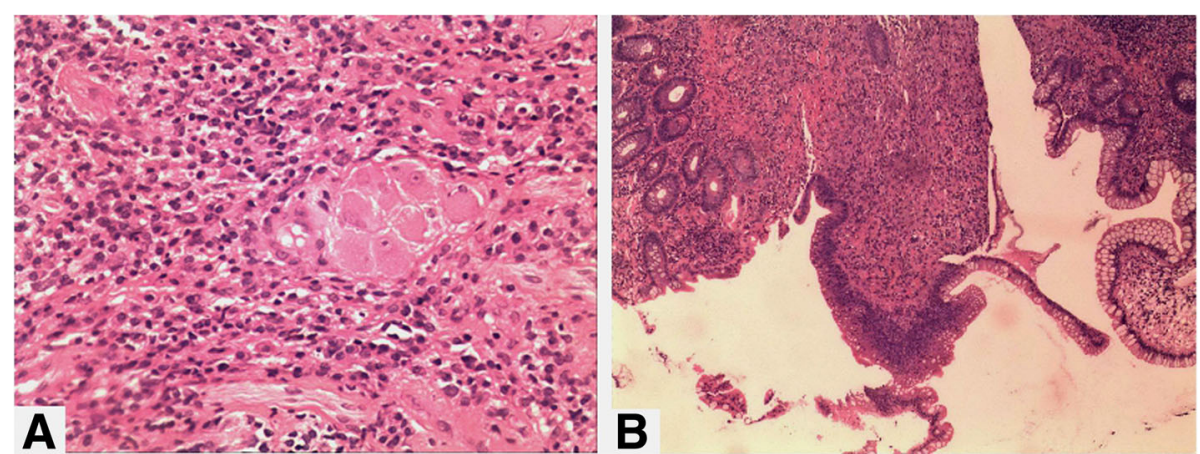

Fig. 3 Intestinal histopathology showed ganglion cells, Inflammatory cell infiltration (a) and crack shape ulcer (b)

with angiography showed there was gastric-intestinal fistula (Fig. 4). Electronic colonoscopy showed no significant improvement compared with the previous, intestinal ulcer surface covered with white moss (Fig. 5). The patient had severe abdominal pain soon, we considered there was digestive tract perforation and recommended surgery, his family members refused further treatment due to economic reasons and he died after one day.

\section{Discussion and conclusions}

The American College of Rheumatology (ACR) established eleven criteria in 1982, which were revised in 1997 as a classification tool for implementing SLE definitions in clinical trials [3]. If a person has any 4 out of 11 symptoms, he is with SLE. In our case, the old male meets five criteria: (1) oral ulcer; (2) polyserositis including pleural effusion, ascites and, pericardial effusion; (3)anemia; (4) positive serology for antiphospholipid antibody and syphilis; (5) positive antinuclear antibody titer of 1:3200. From the above, the patient with SLE is clear. The multiple intestinal ulcers need differential diagnosis between $C D$ and lupus enteritis. CD is a chronic and disabling inflammatory disease of the digestive system of unknown etiology. The incidence of CD is highest in the Northern Europe, more and more young people have been diagnosed CD in
China recently [4]. The diagnosis of CD is established by a combination of clinical symptoms, endoscopic appearance, radiology and histology. Chronic diarrhea is the most common symptom in $\mathrm{CD}$. The most significant endoscopic features of $\mathrm{CD}$ are discontinuous involvement, anal lesions, and cobble stoning. CT is an imaging technique with the highest diagnostic accuracy for the detection of intestinal involvement and penetrating lesions in $\mathrm{CD}$, the features of $\mathrm{CD}$ are dilation, tortuosity, prominence and wide spacing of mesentery with mesenteric arterial which called comb's sign [5]. Focal crypt irregularity and granulomas are the generally accepted pathological features. There are some aspects support CD: (1) chronic diarrhea; (2) marked thickening of the entire colonic mucosa; (3) pathological tend to CD. However, there are some opposed points: (1) old male and short disease course; (3) endoscopic appearance is not totally conformed to $\mathrm{CD}$. There is no consistent definition of lupus enteritis. Some scholars believe that lupus enteritis is the basis of a series of processes, including intestinal vasculitis, mesenteric arteritis, abdominal serositis and lupus peritonitis [6]. Most people think that lupus enteritis is vasculitis or inflammation of the intestinal tract. The most frequent symptoms were abdominal pain and diarrhea. CT and pathology have become the gold standard for
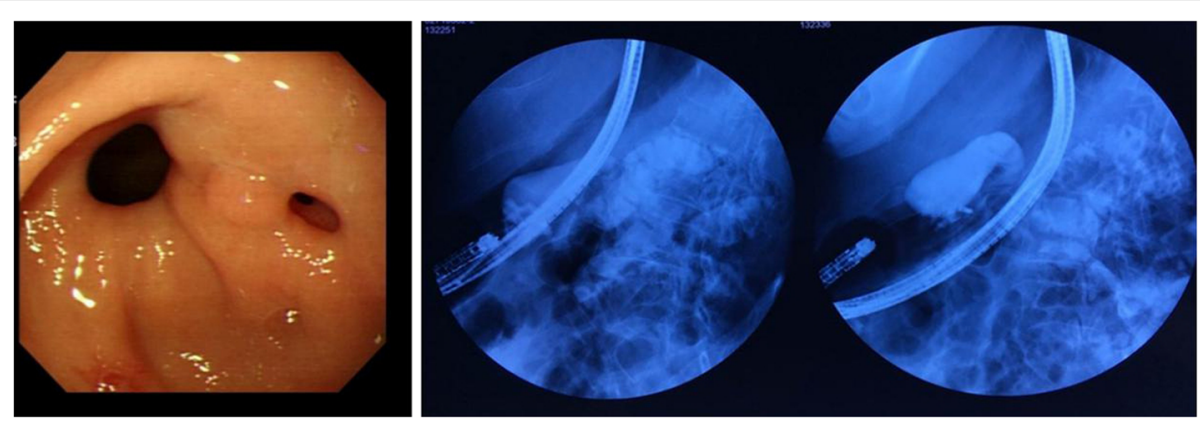

Fig. 4 Gastroscopy combined with angiography showed there was gastric-intestinal fistula 


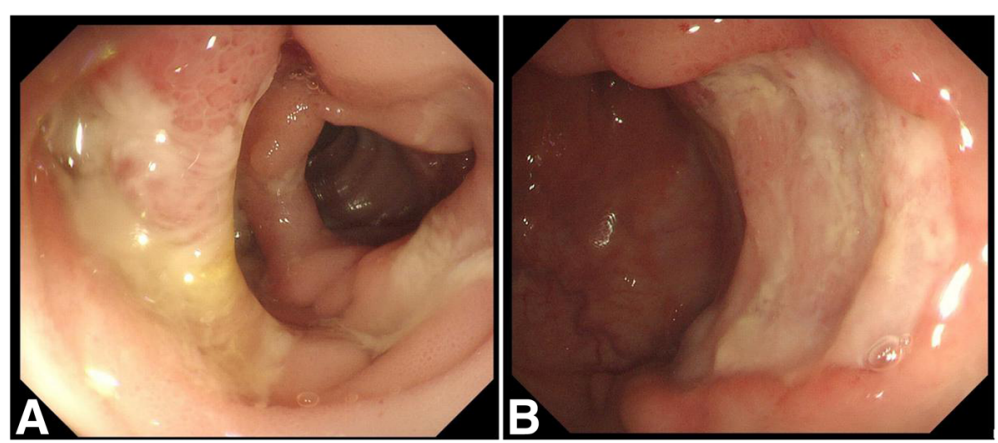

Fig. 5 Electronic colonoscopy showed no significant improvement compared with the previous $(\mathbf{a}, \mathbf{b})$, intestinal ulcer surface covered with white moss (a)

diagnosis [7]. Typical features include bowel dilation, bowel-wall thickening, abnormal bowel wall enhancement (target sign) [8], engorgement of mesenteric vessels with an increased number of visible vessels (comb's sign). These are nonspecific because the above-described abnormalities can also be seen in patients with pancreatitis, peritonitis or $\mathrm{CD}$. There is no unified view about the endoscopic appearance of lupus enteritis, only one Chinese professor described "deep ulcer" in a case report of lupus enteritis. In our case, the ulcers of the terminal ileum and colon are similar to $\mathrm{CD}$ and "deep ulcer" in a few points. On the basis of diagnosis in patients with SLE, the endoscopic appearance was more inclined to lupus enteritis and treatment effect also confirmed this point. Whether SLE can cause gastrointestinal perforation nor not, less reported at present. Oshimo Y [9] reported a case of the elderly man with SLE associated with paralytic ileus and fistula formation in 1999, our case is the first case of SLE with gastric-intestinal fistula.

The differentiation of CD from SLE gastrointestinal involvement may be difficult. In fact, cases with inflammatory bowel diseases like CD could show similar clinical signs and symptoms to SLE, and in some cases of $\mathrm{CD}$ might fulfill some of the classifications of criteria for SLE. With reference to the literature
[10], we listed the following differences between lupus-like Crohn's from lupus enteritis (Table 1).

Steroids are considered to be first-line therapy for lupus enteritis. Depending on the clinical state or other organ involvement, steroid administration may be intravenous or oral, preferably in the case of a severe lupus burst, as tissue edema caused by enteritis may reduce drug absorption [11]. Hydroxychloroquine, azathioprine, mycophenolate mofetil could be considered for long-term maintenance treatment, although it is unclear whether recurrence can be prevented.

Here, we report a case of lupus enteritis masquerading as $\mathrm{CD}$ which indicated us there are some similar points between lupus enteritis and CD. Firstly, "comb's sign" can be shown in CT of lupus enteritis or CD. Secondly, ganglion cell is not specific for the $C D$ which can be seen in lupus enteritis. Lastly, the two diseases have similar clinical symptoms including abdominal pain and diarrhea. The endoscopic appearance of lupus enteritis is nonspecific, on the basis of our case, the features of lupus enteritis can be described as spacious, clean and no moss ulcers which discontinuous involved all gastrointestinal tract. More research and cases are needed to further identify the incidence, clinical manifestations, imaging characteristics and endoscopic appearance of lupus enteritis.

Table 1 The Differences between Lupus-like Crohn's disease and Lupus Enteritis

\begin{tabular}{lll}
\hline & Lupus-like Crohn's disease & Lupus Enteritis \\
\hline $\begin{array}{l}\text { Clinical } \\
\text { Presentation }\end{array}$ & No specific (abdominal pain, diarrhea) & No specific (abdominal pain, nausea and vomiting) \\
$\begin{array}{ll}\text { Abdominal CT } \\
\text { scan }\end{array}$ & Comb's sign, Segmental bowel stenosis & $\begin{array}{l}\text { Comb's sign, Target sign, Pseudoobstruction, Segmental bowel } \\
\text { dilatation }\end{array}$ \\
$\begin{array}{ll}\text { Endoscopy } \\
\text { Therapy }\end{array}$ & $\begin{array}{l}\text { Cobblestone changes, Segmental and jumping lesions } \\
\text { 5-ASA, Corticosteroids, Immunosuppressants, Biological }\end{array}$ & $\begin{array}{l}\text { Multiple round- or oval-shaped discrete ulcers. } \\
\text { Corticosteroids, Immunosuppressants, }\end{array}$ \\
\hline
\end{tabular}




\section{Abbreviations}

CD: Crohn's disease; CRP: C-reactive protein; CT: Computed tomography; ESR: Erythrocyte sedimentation rate; SLE: Systemic lupus erythematosus

\section{Acknowledgments}

This work was partly supported by Dr. Chuan-Ying Li, Hang-Cheng Zhou from the Department of Pathology of the Anhui Provincial Hospital. They performed the histological and pathological diagnostic investigations.

\section{Authors' contributions}

$\mathrm{QMW}, \mathrm{XLZ}, \mathrm{SC}, \mathrm{KGZ}$ and $\mathrm{XMX}$ were involved in the clinical treatment of the patient. XLZ designed the case report and drafted the manuscript. All authors contributed to interdisciplinary interpretation of clinical, radiological and pathological findings, edited the manuscript for important intellectual content and approved the final version.

\section{Authors' information}

All of the authors currently work in the Department of Gastroenterology, Anhui Provincial Hospital, China.

\section{Funding}

There was no funding for this paper.

\section{Availability of data and materials}

The datasets used and/or analysed during the current case reports are available from the corresponding author on reasonable request.

\section{Ethics approval and consent to participate}

All procedures performed were in accordance with the ethical standards of the institutional and/or national research committee and with the 1964 Helsinki declaration and its later amendments or comparable ethical standards.

Oral informed consent was obtained from the patients for publication of this case report and any accompanying images.

\section{Consent for publication}

During lifetime, patients consented orally to the use of their history and all the related images and information for scientific purposes. After the patients' death the patients' next of kin gave written consent for the publication of the cases.

\section{Competing interests}

The authors declare that they have no competing interests.

Received: 10 January 2018 Accepted: 29 July 2019

Published online: 27 August 2019

\section{References}

1. Lisnevskaia L, Murphy G, Isenberg D. Systemic lupus erythematosus. Lancet. 2014;384(9957):1878-88.

2. Assche GV, Dignass A, Panes J, et al. The second European evidence-based consensus on the diagnosis and management of Crohn's disease: definitions and diagnosis. J Crohn's Colitis. 2010;4:7-27.

3. Hochberg MC. Updating the American College of Rheumatology revised criteria for the classification of systemic lupus erythematosus. Arthritis Rheum. 1997;40(9):1725.

4. Kawalec P, Mikrut A, Wiśniewska N, Pilc A. Tumor necrosis factor-a antibodies (infliximab, adalimumab and certolizumab) in Crohn's disease: systematic review and meta-analysis. Arch Med Sci. 2013;9(5): 765-79

5. Minordi LM, Vecchioli A, Guidi L, Poloni G, Fedeli G, Bonomo L. CT findings and clinical activity in Crohn's disease. Clin Imaging. 2009;33(2):123-9.

6. Tian XP, Zhang $X$. Gastrointestinal involvement in systemic lupus erythematosus: insight into pathogenesis, diagnosis and treatment. World J Gastroenterol. 2010;16(24):2971-7.

7. Janssens P, Arnaud L, Galicier L, et al. Lupus enteritis: from clinical findings to therapeutic management. Orphanet J Rare Dis. 2013;8:67.

8. Murosaki T, Nagashima T, Matsumoto K, Minota S. Marked Colonic Wall thickening in lupus enteritis. Intern Med. 2012;51:1451.
9. Oshimo Y, Harada W, Kariya K. A case of elderly man with systemic lupus erythematosus (SLE) associated with paralytic ileus and fistula formation. Nihon Shokakibyo Gakkai Zasshi. 1999;96(4):413-7.

10. Katsanos KH, Voulgari PV, Tsianos EV. Inflammatory bowel disease and lupus: a systematic review of the literature. J Crohns Colitis. 2012;6(7):735-42.

11. Franchin G, Diamond B. Pulse steroids: how much is enough? Autoimmun Rev. 2006;5(2):111-3.

\section{Publisher's Note}

Springer Nature remains neutral with regard to jurisdictional claims in published maps and institutional affiliations.

\section{Ready to submit your research? Choose BMC and benefit from:}

- fast, convenient online submission

- thorough peer review by experienced researchers in your field

- rapid publication on acceptance

- support for research data, including large and complex data types

- gold Open Access which fosters wider collaboration and increased citations

- maximum visibility for your research: over $100 \mathrm{M}$ website views per year

At $\mathrm{BMC}$, research is always in progress.

Learn more biomedcentral.com/submissions 